\title{
A Motherland That One Cannot Return to \\ —An Interpretation on Song of The Chu From a Perspective of Cultural Security
}

\author{
XIONG Xiao \\ Central China Normal University, Wuhan, China
}

\author{
YANG Xi \\ Wuhan College of Foreign Languages and Foreign Affairs, \\ Wuhan, China
}

\begin{abstract}
Song of The Chu, a novel written by LAN Zi- a Chinese Australian writer, recounts the struggle in Australia over 20 years (1988-2008) of a group of Chinese young people. Cultural difference or even conflict is one of the inevitable issues in terms of migration. The Chinese (Han) culture which belongs to the continental civilization and the Australian (Western) culture which belongs to the maritime one are both mighty and cannot be conquered or assimilated by each other. This means that the Chinese immigrants to Australia, compared to the ones from a less mighty culture, are more sensitive and resistant to the impact of an alien culture, which leads to a conscious or unconscious sense of security of the mother culture. Cultural security, not unidirectional, also refers to the worry by the locals of the impact brought by the immigrants. The protagonist resorts to converting to Buddhism as a solution to the cultural schizophrenia.
\end{abstract}

Keywords: Song of The Chu, cultural security, cultural schizophrenia, solution

\section{Introduction}

A human being is a social being, or, as a matter of fact, a cultural being. A human being's nationality is, to a great extent, determined by the culture she/he belongs to rather than the passport she/he bears. Cultural confrontations and conflicts, which are inevitable in the era of globalization, are often reflected in the individual beings who migrate from one nation to another. Some immigrants are able to adapt to the new culture without much difficulty, while some are not. Cultural factors are the first to be taken into consideration with individual differences excluded. The immigrants from Southeast Asia tend to adapt to the new culture more easily than those from China. Small in area and some islands, Southeast Asian nations can easily be influenced and even conquered by other cultures (the Chinese culture before 17th century and the western one after), which leads to a less solid subjectivity of the Southeast Asian culture. The Chinese culture, belonging to the continental

\footnotetext{
* Acknowledgements: This essay is a stage achievement of "A Study on the Chinese Australian Literature from a Perspective of Cultural Security" supported by “the Fundamental Research Funds for the Central Universities of China 2014”, Project Number: CCNU14A03035.

XIONG Xiao, lecturer, School of Foreign Languages, Central China Normal University.

YANG Xi, lecturer, Faculty of Foreign Languages, Wuhan College of Foreign Languages and Foreign Affairs.
} 
civilization, solid and mighty, cannot be easily conquered, which is reflected in that most Chinese immigrants insist in speaking Chinese, living and thinking in the Chinese way even many years after they migrated to another nation. This is the representation of the security of the Chinese culture. "Cultural security" mainly refers to " "the sense of security' that people believe their own country-nation's 'basic values' and 'cultural characteristics' will not vanish or deteriorate in the trend of globalization”"1 (PAN, 2007, p. 28).

The history of the Chinese immigration to Australia can be dated to the early 19th century, however, most early Chinese immigrants worked as miners, cooks, shepherds and forth who belonged to the lower class and barely had any access to uttering their voices, let alone in the form of writing. The Chinese Australian writing gains prosperity with the rising of multiculturalism since the 1970s when the White Australian Policy was demolished.

The novel Song of The Chu written by LAN Zi recounts the life struggle of a group of Chinese young people who migrated to Australia in the 1980s, their effort to adapt to the Australian culture and the dilemma between staying in Australia and returning to China. The Chinese immigrants' experiences and destinies in Australia, though individually different, are largely related with the Chinese culture.

\section{The Adaptation to the Australian Culture}

Culture, in fact not a big word, is pervaded in one's daily life, which can reflect the basic outlook on value and the traits of a culture, including how a nation's language is constructed and used, how its people cook and enjoy food, and how its people deal with job (money) and interpersonal relationship.

The moment when the Chinese people step onto the land of Australia, the first shock comes from the language they hear and read and they can barely communicate with the local residents without speaking English. In other words, they can barely live in the Other culture without acquiring the Other language. "Attending the class of English training school is pleasant”2 (LAN, 2011, p. 12). Therefore, the first task for most Chinese immigrants is to get language training. Language is one of the best representations of culture in that

Language is not merely the vehicle for thinking or the means of communication, it also bears the weight of people's consciousness, thinking, mind, emotion and the formation of personalities and passes on the historical traces of the formation and development of innumerable families, races, nations and countries; it is the historical and cultural geological stratification of a country-nation. ${ }^{3}$ (PAN, 2007, p. 121)

People take in and express most kinds of information by and with language, which is a highly abstract system of symbols. Linguistically, Chinese is built on characters which, through the grapheme, can be understood but cannot be pronounced; whilst English is built on words which, through the grapheme, can be pronounced but cannot be understood (except knowing the meanings of roots and affixes). Furthermore, English belongs to the German language branch of the Indo-European language system whilst Chinese the Sino-Tibetan language system. The two belonging to different language systems and the English-speaking nations being far from China, it is not easy for the Chinese people to acquire English, even the immigrants to an English-speaking nation, like Australia. Compared to the Europeans, it may take the Chinese immigrants longer to acquire English and it is not

\footnotetext{
1 The citation is translated by the authors (XIONG Xiao and YANG Xi).

2 The citation is translated by the authors (XIONG Xiao and YANG Xi).

3 The citation is translated by the authors (XIONG Xiao and YANG Xi).
} 
uncommon that some Chinese immigrants (for example, those who live in the China town) who have stayed in Australia for many years still cannot speak fluent English or would keep speaking Chinese and do not often communicate with the local residents. Learning English is a tough but inevitable task for most Chinese immigrants.

I went to an English school when I just arrived in Sydney. The students there were promoted to a higher level every three months. Six months later, I was promoted from the beginners' class to the advanced one, which was a preparatory course for the undergraduate or postgraduate studies. ${ }^{4}$ (LAN, 2011, p. 19)

When one begins learning another language, the culture encoded within is being constructed in one's mind. Besides language, food is also one of the best representations of culture.

When I just arrived in Australia, the thing that I was not used to the most was not language or quietness...it was food. It is said that one thinks of her/his dearest ones far away on festive occasions more than ever, as for me, it is thinking of the chicken - the flavor of home. ${ }^{5}$ (LAN, 2011, pp. 154-155)

As a matter of fact, food is better to be replaced by "cuisine” which culturally stresses more on the ways of selecting, cooking, and enjoying food. In other words, food, like language, no longer mere food, has been invested with cultural traits. Most Chinese immigrants can stand many different things in the Other nation, however, the Chinese food is what they cannot forget or live without. They can live on hamburgers, chips, and sandwiches for at most one month and if longer they may get crazy. An Ping and her friends get together from time to time to prepare and have the Chinese food such as jiaozi. Varieties of the Chinese cuisines (Chuan, Lu, Yue, and Huaiyang) and of the cooking styles (panfry, stirfry, fry, boil, steam and so forth) always attract and haunt the stomach and the mind of the Chinese people overseas. It is very uncommon to find a Chinese immigrant insisting cooking in the western style and enjoying the western food for years, sometimes though. Some Chinese immigrants think the Australians do not treat their stomach seriously for they only stuff it with a sandwich for lunch. When the Chinese immigrants gather together, they do not only talk in the language of Chinese, but also cook and enjoy the Chinese food, where language and food mix with each other and become the symbols of homesickness.

There are common experiences for both Chinese women and men immigrants; but sometimes different. Living far away from the Motherland, the Chinese immigrants may fall into frequent homesickness which may lead to their gatherings from time to time. "Why is everyone here today?”6 (LAN, 2011, p. 17). "Oh, today is the Chinese New Year's Eve”7 (LAN, 2011, p. 17). “Zhong Yun may call me when he is free; he occasionally comes to attend our party”, (LAN, 2011, p. 20). Chinese women and men may become friends or start a relationship to comfort each other and to dispel the homesickness. "According to figures, the sex ratio of men to women is 8: 1 "9 (LAN, 2011, p. 20). But there are always more options for Chinese women for they can establish a relationship with the Australian men ("Even worse, the women students out of the 8:1 aim at laowai (foreigners)"10 (LAN,

4 The citation is translated by the authors (XIONG Xiao and YANG Xi).

5 The citation is translated by the authors (XIONG Xiao and YANG Xi).

6 The citation is translated by the authors (XIONG Xiao and YANG Xi).

7 The citation is translated by the authors (XIONG Xiao and YANG Xi).

8 The citation is translated by the authors (XIONG Xiao and YANG Xi).

9 The citation is translated by the authors (XIONG Xiao and YANG Xi).

10 The citation is translated by the authors (XIONG Xiao and YANG Xi). 
2011, p. 18)), the men from other developed nations or the Chinese men from Hongkong, Taiwan, or Southeast Asia as Mike says: "You can marry a man. You can marry a rich laowai, to kill two birds with one stone, citizenship settled and becoming rich”"11 (LAN, 2011, p. 23). Compared with Australia, China is a developing country. The economic status plays an important role in the relationship between different sexes. The inferior economic status of the Chinese immigrants determines that more Chinese women immigrants marry or would marry the white Australian men while few Chinese men immigrants marry or would marry the white Australian women. "Love has to be fed with milk and bread rather than 'love is rose to be frequently watered' as in a song"12 (LAN, 2011, p. 47). Although the economic status works, sometimes it is not easy, as a matter of fact, for a Chinese woman to marry a laowai. Audrey tells An Ping:

We met that day and had a nice chat...I thought it was time to go home. Unexpectedly, he took me to a motel. I told him he couldn't do that to me and asked him to drive me home. ${ }^{13}$ (LAN, 2011, p. 27)

Inequality in economic status leads to the inequality of the relationships between laowai and the Chinese women. There are also Chinese men getting married with the women from other nations, Zhong Yun, who marries a (non-white) Vietnamese woman, being one. It is not seldom that the Chinese women and men start a relationship, An Ping and Zhang Tao and Audrey and David being two examples, which, unfortunately, do not turn out to be happy endings, An Ping and Zhang Tao part and Audrey dies. Although it is rumored that the Chinese women want to marry the white men, the fact is that few do and most marry Chinese men instead. Even An Ping's marriage to a man from Hongkong ends as a tragedy. A marriage of persons from two nations is just like the confrontation between two cultures they represent. The reason that most Sino-Australian mixed couples part in the end is because the incompatibility of the two cultures they respectively bear.

The adaptation of the Chinese immigrants to the Australian culture is not easy due to the powerfulness of the Chinese culture and the conscious or unconscious cultural defense, represented by the Chinese language which is deeply rooted in the linguistic function of the Chinese immigrants' minds, the Chinese food which they cannot live without, their tendency of gathering together and the interlaced interpersonal relationships.

\section{The Return to the Chinese Culture}

Having stayed for some years in Australia, An Ping said to herself:

Without love, family, or career, I have become a loner in the real sense. I am bored enough so that I read through the newspaper that Mike told me to bring back. It read 'welcome the professionals with Master Degree or above who are willing to return to China to work or start a business to attend the meeting'. Shall I sign up to the meeting? Shall I return? ${ }^{14}$ (LAN, 2011, p. 141)

"Love”, “family”, and "career” are the symbols of belongingness. No matter how long the first-generation Chinese immigrants have stayed in Australia, it is always not easy for them to find a sense of belonging to Australia and they never disconnect with their Motherland. When they encounter setbacks, they would resort to China or the Chinese culture for revitalization. For them, there are love, family, and career in the Motherland.

11 The citation is translated by the authors (XIONG Xiao and YANG Xi).

12 The citation is translated by the authors (XIONG Xiao and YANG Xi).

13 The citation is translated by the authors (XIONG Xiao and YANG Xi).

14 The citation is translated by the authors (XIONG Xiao and YANG Xi). 
At the Christmas of 2000, I arrived with my luggage at Baiyun Airport of Guangzhou. I stepped again onto the land of Mainland China 12 years and one month after I left. I didn’t know why I had such a feeling: among all the returnees from all over the world, I especially wanted to see the ones who were from Australia and regarded them as townees. Did it reflect the territorial complex in human nature: Abroad, we regarded the Chinese people as compatriots; At home, we regarded those who were from the same city or province as townees - the ones on our own side. ${ }^{15}$ (LAN, 2011, p. 154,)

According to Hinduism and Buddhism, 12 years constitute a Samsara. An Ping's return 12 years after she left marks a new journey in her life or a rebirth. The 12-year drifting in Australia has not completely Australianized her, therefore, she returns to China to rediscover her Chineseness. For the Chinese immigrants, "in the process, however, they find that the one has become the other to such a degree that otherland actually contains motherland, like a mirror with a mirror” (OUYANG, 2004, p. 50). Upon her return, some things have changed, some not, both for her and for China. She encountered the Chinese IT elites who came back from the U.S. "Their return to China was like rich men, with superiority, visiting poor relatives”16 (LAN, 2011, p. 165). They had stayed in the U.S. which was more economically and technologically developed than China. Naturally they thought they had been endowed with the Americanness and displayed an air of superiority which reflected that they were different from their compatriots and they may even look down upon the latter. Accordingly, surprisingly and probably, their compatriots may admire and even envy them as if they were the authentic white American citizens. Naturally, An Ping, who returned from Australia felt less confident and marginalized among them. An Ping regarded the ones who returned from Australia as her compatriots (the ones "on her side") rather than the Chinese people. This implies she has been endowed with some Australianness or has been somewhat Australianized. But China is where she was born, she could not completely disconnect with her past, her family, and friends. Therefore, "I started looking for a job after I came back (to Australia ${ }^{17}$ ) from Guangzhou. I laid my eyes on those Australian companies who had sub-branches in China"18 (LAN, 2011, p. 169). 12 years in Australia did not scour An Ping's Chineseness, instead, pushed her forward to resorting to the things and people (Zhang Tao being one) in China when she felt upset and lost.

An Ping returns to China several times since then, for work and also for Zhang Tao. For her company and boss, her Chinese identity plays a role of bridge to connect and earn profits from the Chinese people; for the sub-branch in Beijing, she is a Chinese Australian who must be close to the Chinese people and can help them earn profits from the Australian company. Mayo, her boss, does not trust the Chinese people and asks An Ping to fly to Beijing to audit the account.

Waiting for the financial statements from the sub-branch in Beijing, Mayo was preparing for the company's listing. I didn't have much time to think of Zhang Tao. With a different division of the Australian fiscal year from the Chinese one, Mayo does not trust the sub-branch in Beijing. The Australian accounting system inheriting the British one, an Australian fiscal year begins on the 1st July of this year and ends on the next 30th June while the Chinese one begins on the 1st January of this year and ends on the 31st December of the same year. The accounting software that the Sub-branch in Beijing uses is developed in China while the Australian one in Australia. That is to say either has an account. He asked me to reenter the data that I brought back from Beijing. I worked overtime for two months to rewrite the Chinese

\footnotetext{
15 The citation is translated by the authors (XIONG Xiao and YANG Xi).

16 The citation is translated by the authors (XIONG Xiao and YANG Xi).

17 Noted by the authors.

18 The citation is translated by the authors (XIONG Xiao and YANG Xi).
} 
account. $^{19}$ (LAN, 2011, p. 192)

Mayo's distrust against the Chinese people can be dated to long ago, which is under the influence of stereotyping the Chinese people. An Ping gives her comment "He (Mayo) was doomed to invest in China for that he could never feel the pulse of the Chinese people”20 (LAN, 2011, p. 210). However, China has been developing and changing and it is no more the one when An Ping left China twelve years ago. What An Ping sees in China has subverted the long-standing stereotyped exoticization of China in the western literature. There must be some differences between cultures and some problems in the Chinese ways of dealing with things, but it should not be the ground that the westerners prejudice against the Chinese people. It's just because each has a unique and solid culture.

The Chinese people in the Beijing sub-branch at first regards An Ping as an authentic compatriot and want to take advantage of her by not complying with the rules and she also finds that her ways of dealing with things conflict with the Chinese ones. However, as An Ping puts "Educated and growing up in Australia, my intestine has been straightened"21 (LAN, 2011, p. 269), whose straightforwardness is one of the representations of the western culture and maritime civilization. Although An Ping does not like Mayo very much neither, she prefers the rules and the ones who respect and comply with the rules. Compared with the Chinese people, Mayo is the one who more respects the rules. No one should be blamed with regard to the differences of the ways in dealing with things between the Chinese and the Australian peoples. It is the culture that functions. The Chinese culture, belonging to the continental civilization, has been focusing more on the interpersonal relationships rather than on rules. China has just opened its gate for more than 30 years and it's on the process of being civilized and standardized and the so-called international rules and standards are made by the western world which includes Australia. Therefore, it is no wonder that An Ping, who has stayed in Australia for years, have differences and even conflicts with her Chinese compatriots, which should not be understood as "home-resentment" (WANG \& ZHAO, 2005, p. 78).

I kept asking Mayo: “When can I return to Sydney. I’ve already missed Australia”. I have been dreaming of returning to China before this, never regarding Australia as my home though I have stayed there for more than 10 years which almost count for half of my life. Now I have returned only to find the so-called Otherland is my present home and China has become the "Motherland" that only lives in my memories. In the eyes of my compatriots, I have become one of "Mayo's", "one of the Australian company" and one on their opposition who wants to pick a hole in their account. ${ }^{22}$ (LAN, 2011, p. 270)

The process of migrating is a drifting on an Otherland. 12-year dream of returning to the Motherland only ends with the Motherland turning into another "Otherland" while the Otherland in a real sense has somewhat become a new "Motherland". The return to China does not bring An Ping close to her Chinese compatriots or re-endow her with the Chineseness, but only strengthens her sense of belonging to Australia.

In the Motherland which has turned to the Otherland, Zhang Tao, who has been her lover in Australia and returned to China for his official career, is her only spiritual sustenance. Zhang Tao has stayed in Australia for

\footnotetext{
19 The citation is translated by the authors (XIONG Xiao and YANG Xi).

20 The citation is translated by the authors (XIONG Xiao and YANG Xi).

21 The citation is translated by the authors (XIONG Xiao and YANG Xi).

22 The citation is translated by the authors (XIONG Xiao and YANG Xi).
} 
years as other overseas Chinese students, only finding his personality more compatible with the Chinese culture and returns to China. Zhang Tao is one of the reasons of her return to China but it only turns out to be that Zhang Tao has got married and fathers a son. She cannot keep an illegal and immoral relationship with him. Zhang Tao says: “An Ping, there is no such a supposition. One cannot step twice into the same river. You understand it. We cannot return to the past" ${ }^{\text {23 }}$ (LAN, 2011, p. 192) An Ping rebuts: "Yes, you can. If you are willing to, you can return to Australia with me and we can live as we have lived in the past..."24 (LAN, 2011, p. 192). For Zhang Tao, his Chineseness has never faded away; for An Ping, her Chineseness has partially, if not fully, faded away and that is why she returns Australia.

An Ping does not find a sense of belonging on returning to China and her love for Zhang Tao is doomed with no future. Therefore, her two sources of belonging recede into disillusion and she returns to her new Motherland-Australia.

\section{A Solution to Cultural Schizophrenia}

Compared with An Ping's first journey to Australia, her decision to return to Australia is somewhat like self-exile. Edward Said gives a definition to exile in his Representations of the Intellectual:

The exile therefore exists in a median state, neither completely at one with the new setting nor fully disencumbered of the old, beset with half-involvements and half-detachments, nostalgic and sentimental on one level, an adept mimic or a secret outcast on another. (Said, 1993, p. 49)

To be Chinese or to be Australian, that is the question. Within the narrow space between the two cultures and with the unreachable love from Zhang Tao and the irremediable death of Zhong Yun, An Ping feels lost and helpless and thus "I became superstitious, looking for fortune-tellers everywhere. A friend of mine introduced an old western lady to me and said that she could tell the past and the future and the previous and the present life,25 (LAN, 2011, p. 169). Resorting to fortune tellers is a symbol of seeking a sense of belonging which is absent in real life, or rather, An Ping finds her consciousness barely not able to bear her existence, therefore, she turns to something unconsciousness ("I became superstitious"). "Myth is the natural and indispensable intermediate stage between unconscious and conscious cognition” (Jung, 1961, p. 311). Fortune telling or Divination, not a formal religion, can be dated to primeval ritual which was closely related with myth and bridged a connection between the unenlightened humankind and the gods. Generally, fortune telling, which existed or exists among the polytheistic tribes or ethnic groups, is different from a formal and systematic religion with a rigid hierarchy. However, it is the only way which must be passed from polytheism to monotheism in the process of humankind civilization for that the former is more structurally unstable. It is also reflected in An Ping's suspicion about what the fortune teller says.

A young Chinese gentleman knocks at An Ping's door, saying “I'm a Buddhist, not a bad guy. If you're free, please come to our Buddhist temple”26 (LAN, 2011, p. 259), which leads An Ping to the access to Buddhism for the first time. An Ping's conversion to Buddhism is rather schematized, which reflects that at first she does not

\footnotetext{
23 The citation is translated by the authors (XIONG Xiao and YANG Xi).

24 The citation is translated by the authors (XIONG Xiao and YANG Xi).

25 The citation is translated by the authors (XIONG Xiao and YANG Xi).

26 The citation is translated by the authors (XIONG Xiao and YANG Xi).
} 
take the conversion too seriously neither. However, An Ping has failed to place her spiritual sustenance on returning to China and Zhang Tao and on returning to Australia and Zhong Yun who is in Australia but has got married, converted to Catholicism and died. With disillusionments in both China and Australia, in both Zhang Tao and Zhong Yun, in the tragic marriage and divorce with a Hongkong man and with more-than-ten-year struggle for life in Australia,

I kneel on the mat and could not hold back the tears. I lower my head so that no one could see my inexplicable sorrow and talk to Buddha in my heart: "The Mighty and Merciful Buddha, please give me wisdom so that I can confront with my star-crossed destiny; please give me strength so that I can endure the trauma brought by love”. ${ }^{27}$ (LAN, 2011, p. 265)

From being superstitious to believing in Buddha, An Ping's consciousness overcomes unconsciousness, grows and lays itself on a more stable monotheism—Buddhism.

An Ping does not only convert to Buddhism, but also decides to be a voluntary worker for the Buddhist temple in Nepal. As the Master says: "You have to learn to let go. Shede, shede, the hand that gives gathers”28 (LAN, 2011, p. 326). She obeys, lets go her bewilderment in the cultural schizophrenia and even flies to Lumbini where Buddha was born and where An Ping comes to an insight:

Why Buddhism came into being in such a place and why Buddhism requires one to cultivate the afterlife. It is the ones who live here that long for the afterlife; long for not being a human being; long for not being a woman; long for a paradise where one does not need to worry about food or clothes, where one has water to drink and where the sun is not burningly hot and it is not cold in winter. The reality is so disappointing. ${ }^{29}$ (LAN, 2011, p. 328)

It is right at Lumbini that An Ping realizes that her living condition is far better than the locals' and how blessed she is. Moreover, upon seeing the sunset at the Himalaya, her bewilderment on cultural identity and love is melted.

An Ping converts to an eastern religion rather than a western one, which helps her survive the migration from her Motherland to the Otherland though she cannot fully incorporate with the white Australians and neither can she be identified with by her authentic Chinese compatriots. It is Buddhism that gives her strength and it is a solution she finds to let go the bewilderment and to cure her cultural schizophrenia.

\section{Conclusion}

Most immigrants, in the process of immigration, have to undergo the three stages experienced by An Ping, especially for the Chinese immigrants who are from a solid and powerful culture. When they feel they are narrowed between two cultures, they must also suffer from the cultural schizophrenia and want to find a solution to their vague cultural identity. Converting to Buddhism is definitely not the only solution; more solutions to this issue can be found out in the studies on other Chinese Australian writings.

\section{References}

Jung, C. G. (1961). Memories, dreams, reflections. New York: Vintage Books. LAN, Z. (2011). Song of the Chu. Kingsbury (Australia): Otherland Publishing.

${ }^{27}$ The citation is translated by the authors (XIONG Xiao and YANG Xi).

28 The citation is translated by the authors (XIONG Xiao and YANG Xi).

29 The citation is translated by the authors (XIONG Xiao and YANG Xi). 
OUYANG, Y. (2004). Motherland, Otherland: Small issues. Antipodes, 18(1), 50-55.

PAN, Y. H. (2007). Cultural security. Hangzhou: Zhejiang University Press.

Said, E. W. (1993). Representation of the intellectual. New York: Vintage Books.

WANG, L. B., \& ZHAO, H. M. (2005). “'Exile’s return’-On home-resentment in Ouyang Yu’s the eastern slope chronicle”.

Journal of PLA University of Foreign Languages, 78-82. 